\title{
Patient in hospital for over a year must leave for community care, says judge
}

\author{
Clare Dyer
}

The BMJ

A UK hospital trust has been granted a High Court injunction requiring an overstaying patient to leave the next day, amid concerns that her bedroom could be urgently needed for a covid-19 patient. $^{1}$

MB, whose identity was protected by court order, was admitted to hospital in February 2019 after collapsing at home. She occupied a bedroom on an acute neuropsychiatric ward intended for stays of no longer than 28 days at the National Hospital for Neurology and Neurosurgery at Queen Square in central London.

MB has a functional neurological disorder with variable limb weakness and tremor, chronic migraine, fatigue, and generalised pain. She has longstanding complex psychological conditions, including post-traumatic stress disorder, disrupted attachment, obsessive compulsive disorder, possible borderline personality disorder, and Asperger's syndrome.

Camden Borough Council in London has been trying to arrange a community care package for the patient for more than a year. The council found a new flat for her, made adaptations that she demanded, and guaranteed 24 hour care, seven days a week, with a review at three months. But she refused to move and kept making more demands.

University College London Hospitals NHS Foundation Trust, which runs the Queen Square hospital, made the application under the law dealing with trespassers and told Mr Justice Chamberlain that it needed the bedroom urgently because of the covid-19 pandemic. The trust argued that MB would be at greater risk of catching covid-19 if she remained in hospital and that she could safely be discharged to the specially adapted flat with a care package, including therapy, that was more than adequate to meet her clinical and other needs.

\section{Intimidating behaviour}

A consultant neurologist at the hospital, Gerry Christofi, told the judge that MB frequently shouted and swore at staff and used threatening and intimidating behaviour, including accusing them of negligence and threatening court action. "Atmosphere has been intimidating, adversarial, calumniating and extremely unpleasant," he said in a witness statement. "These episodes have impacted negatively upon the mental health of several staff members, including my own."

MB was represented by a barrister who argued that she would be at risk of suicide if forced to leave and that, in requiring her to go, the hospital would be breaching human rights law and its duties under the Equality Act. But Chamberlain dismissed those arguments.

He said that hospitals, in allocating scarce public resources, had to weigh up the needs of one patient against those of another. In this case there was not an identifiable other patient, "but the decision to withdraw permission for $\mathrm{MB}$ to remain in the hospital is still a decision about the allocation of scarce public resources," he said.

"Decisions of this kind are a routine feature of the work of hospitals and local authorities, even when there is no public health emergency," Chamberlain explained. "The fact that we are now in the midst of the most serious public health emergency for a century is likely to accentuate the need for such decisions." He said that MB had no history of suicide attempts and that her risk of suicide was moderate to low. She would have 24 hour care, so any deterioration in her mental health would be picked up and specialist support would be provided by the local complex depression, anxiety, and trauma team.

The judge made an order on 9 April requiring that MB must leave the hospital by noon the following day and authorising the trust to take all reasonable steps to effect her discharge, including "transferring the defendant from her hospital bed to an ambulance trolley, transport in the ambulance to her home and transferring the defendant from the ambulance trolley on to her bed."

1 University College London Hospitals NHS Foundation Trust v MB. [2020] EWHC 882 (QB). https://www.bailii.org/ew/cases/EWHC/QB/2020/882.html.

Published by the BMJ Publishing Group Limited. For permission to use (where not already granted under a licence) please go to http://group.bmj.com/group/rights-licensing/ permissions 